\title{
A REDUÇÃO DE PERDAS NUM PROCESSO PRODUTIVO ATRAVÉS DA IMPLANTAÇÃO DA SISTEMÁTICA DA ÁRVORE DE PERDAS
}

\section{LOSSES REDUCTION INTO A PRODUCTION PROCESS BY IMPLEMENTING LOSSES TREE}

\author{
Irlam Reis de Aragão \\ Mestrando em Engenharia de Produção \\ UFSC \\ Rua Maria dos Reis Silva, c1, 117, Lauro de Freitas, BA, CEP 42.700-000 \\ irlam.aragao@braskem.com.br \\ Antonio Cezar Bornia \\ Professor Associado \\ Universidade Federal de Santa Catarina \\ Departamento de Engenharia de Produção e Sistemas \\ UFSC/CTC/EPS, CP 476, Florianópolis, SC, CEP 88.010-970 \\ cezar@deps.ufsc.br
}

\begin{abstract}
RESUMO
O presente trabalho objetiva examinar a aplicação de uma sistemática voltada para a identificação de perdas num processo produtivo: a Árvore de Perdas. De início, toma-se como referência uma abordagem baseada na necessidade da busca pela competitividade da indústria e de como a inteligência gerencial pode realizar um papel diferenciado na sua concretização. A aplicação de metodologias que indiquem os principais focos dos processos produtivos, de maximização da produtividade pela eliminação de perdas, tem sido uma das atividades das empresas modernas. A árvore de perdas é uma sistemática que pode indicar quais são as oportunidades para redução das perdas. A implantação desta metodologia pode levar a empresa a obter vantagens em sua competitividade pela redução de custos de produção, melhoria da qualidade e otimização dos processos produtivos. Este trabalho utiliza um estudo de caso para analisar a implantação da Árvore de Perdas, verificando suas vantagens, benefícios e restrições.
\end{abstract}

Palavras-chave: Qualidade, Produtividade, Árvore de Perdas, Perdas. 


\begin{abstract}
The present work concerns to the study of application of a systematic directed toward the identification of losses in a productive process: Losses Tree. By beginning, the focus of this work is based on the competitiveness needs of the industry and on how the management intelligence can perform a differentiated role in its accomplishment. The application of methodologies that indicate the main focus of the productive processes, like the maximization of the productivity by elimination of losses, has been one of the activities of the modern companies. The losses tree is a systematic that can indicates the main opportunities for reduction of losses. The implementation of the methodology can lead the company to archiving great advantages in its competitiveness within reduction of production costs, improvement of quality and productivity optimization. This work uses a case study to analyze the implementation of the Losses Tree, analysing its advantages, benefits and restrictions.
\end{abstract}

Key-words: Quality, Productivity, Losses Tree, Losses.

\title{
1. INTRODUÇÃ̃O
}

Muito embora o gás natural e o petróleo sejam associados a combustíveis como gasolina e o diesel, esses produtos estão localizados no início de uma cadeia produtiva que gera materiais de conhecimento comum de boa parte da população: os plásticos. O início da cadeia de produção dos petroquímicos dá-se com o processamento da nafta, uma fração retirada do petróleo, ou no gás natural. A primeira geração desta cadeia produtiva tem por objetivo reagir a nafta ou gás natural em altas temperaturas, quebrando a sua estrutura química, transformando-os em eteno, que é matéria prima para a segunda geração. Nessa fase da cadeia de produção, o eteno é reagido de diferentes formas e dá origem aos polietilenos.

Os plásticos em seu estado bruto são, então, processados na terceira geração através de transformações físicas, como fusões e misturas, gerando os utensílios e materiais de conhecimento do público, como embalagens, tubos e conexões, brinquedos, e especialidades diversas. É essa diversidade de aplicações que faz com que autores como Guerra (1993), defendam a idéia de que a indústria petroquímica mundial está localizada de forma estratégica na cadeia produtiva, pelo fato de produzir os insumos, base para toda a estrutura de produção, como embalagens, automóveis, brinquedos e mesmo especialidades em áreas como medicina, construção e saúde.

Um ponto importante que se deve ter em mente num quadro de disputa pelo mercado petroquímico, especialmente em termos globais, é a necessidade do estabelecimento de mecanismos de pesquisa e benchmarking de melhores práticas e performances no mundo - o 
que mantém em permanente estado de desenvolvimento e implantação de melhoria de desempenho - que, no caso da indústria, se percebe principalmente através da melhor utilização da capacidade instalada e da redução dos custos de produção.

A verdadeira função da gestão de qualquer negócio está baseada na geração de resultados empresariais sustentáveis - o que possibilitará a sua sobrevivência, o seu crescimento e a sua perpetuidade. Cabe então às empresas modernas, definir e implantar uma sistemática associada a sua estratégia de negócio que possa identificar os principais pontos de perda no seu negócio e contínua e consistentemente buscar alternativas para eliminá-las ou reduzi-las, agregando valor a todas as partes interessadas, os stakeholders.

Total Productive Maintenance - ou Manutenção Produtiva Total (TPM) visa principalmente a proteção de valor do acionista, resgatando as condições básicas dos equipamentos e garantindo sua confiabilidade, a partir da identificação de perdas no processo produtivo. É sugerida a utilização de uma sistemática que, com base na comparação dos resultados da empresa com algumas referências estabelecidas, possam se identificar os grandes grupos de perda do negócio. A partir desta identificação sistemática, a organização como um todo, deve definir ações para minimizar ou eliminar as perdas identificadas (IMAI, 1997). Essa sistemática de identificação e priorização da eliminação de perdas é conhecida como "Árvore de Perdas".

O objetivo deste artigo é identificar se a aplicação da sistemática da "Árvore de Perdas" do TPM serviu como forma de identificação de perdas e oportunidades para trazer retorno significante a uma empresa do setor petroquímico - estudada.

A próxima seção discute conceitos relativos à manutenção produtiva total e à árvore de perdas. Na seqüência, discorre-se sobre a metodologia utilizada na pesquisa e a implantação da árvore de perdas em uma empresa do setor petroquímico. Finalmente, as conclusões são apresentadas.

\section{A MANUTENÇÃo PRODUTIVA TOTAL E A ÁRVORE DE PERDAS}

Segundo Imai (2000, p.2):

TPM é um método de gestão que identifica e elimina as perdas existentes no processo produtivo, maximiza a utilização do ativo industrial existente e garante a geração de produtos de qualidade a custos competitivos. Também ajuda a desenvolver conhecimentos capazes de reeducar as pessoas para ações de prevenção e melhoria contínua, garantindo o aumento da confiabilidade dos 
equipamentos e a capabilidade dos processos sem a necessidade de investimentos adicionais.

De acordo com Sakaguchi (2001), o foco inicial do TPM baseava-se na melhoria das atividades de produção. A partir de 1989, essa visão foi estendida para incluir melhorias em todos os processos da empresa. O foco da atuação do TPM tem mudado do equipamento para o sistema de produção como um todo. As atividades de redução e previsão das perdas latentes do equipamento tem evoluído para redução e previsão das perdas no sistema de produção como um todo.

Sendo assim, as atividades do TPM têm sido valiosas pela eliminação dos fatores que impossibilitam a redução de custos dos produtos e, consequentemente, dos fatores que reduzem ou impedem o lucro. Neste sentido, o TPM vem sendo uma sistemática indispensável para a criação de um sistema lucrativo de práticas corporativas e de negócio (SAKAGUCHI, 2001).

Para Suzuki (1994), no âmbito da gestão das operações, os custos normalmente atribuídos são compostos pelas despesas com material, pessoal, gastos com contratações de terceiros, despesas com materiais de consumo, despesas com materiais de aplicação e os investimentos necessários a atualização tecnológica.

Segundo Takahashi e Osada (1993), deve-se investigar a eficiência dos ativos produtivos segundo a utilização da sua capacidade de projeto e segundo os índices de qualidade dos produtos gerados. Assim, para diagnosticar as perdas reais de um ativo produtivo, deve-se atentar para alguns indicadores como: índice de utilização, tamanho do estoque de material acabado, material em processo e demais índices de utilização de material na linha de produção. Os autores propõem o modelo exposto na figura 1 para verificação do rendimento global do equipamento. 


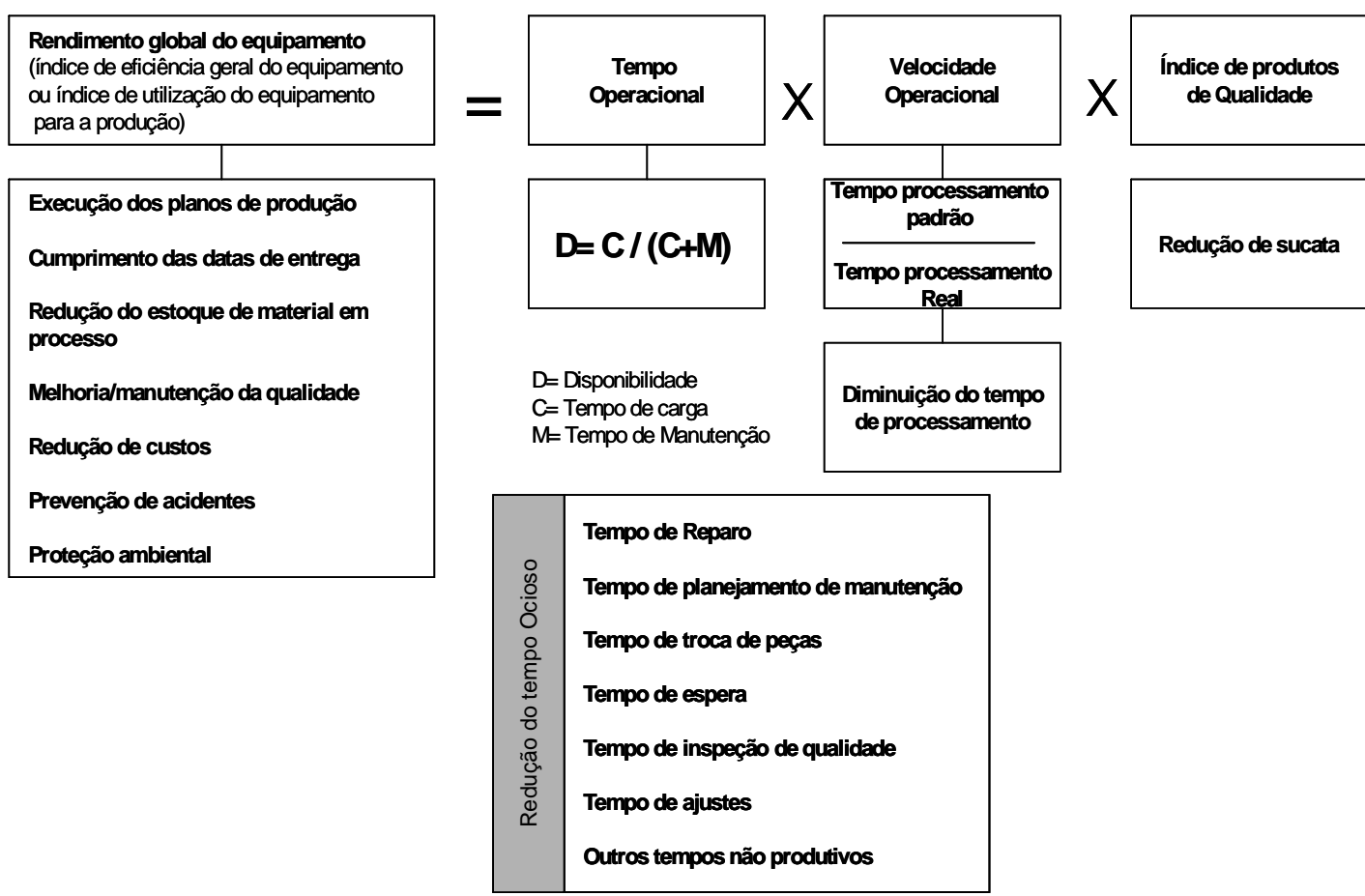

Figura 1 - Rendimento Global do equipamento (fonte: Takahashi e Osada, 1993, p. 45)

Para os autores, caso se deseje questionar e desafiar os dados gerenciais de forma apropriada, no que se refere ao gerenciamento da qualidade, à utilização do equipamento, aos materiais em processo ou aos custos, é necessário estar totalmente familiarizado com as metas estatísticas e suas referências. De modo geral, segundo essa perspectiva, as fábricas lucrativas não necessariamente possuem os equipamentos mais novos. Ao contrário, as mais antigas, se bem geridas podem agregar maior valor aos acionistas, uma vez que não pagam encargos de juros e amortizações. Muitas reduções de custos de processamento foram sendo obtidas através de um número significativo de inovações parciais procurando-se explorar ao máximo as formas de utilização dos ativos existentes (TAKAHASHI e OSADA, 1993).

Para Carrijo (2001), as perdas relacionadas à manutenção e operação, oriundas da indisponibilidade operacional, da vazão não otimizada, dos re-trabalhos e refugos, dos gastos com energia e demais utilidades, multas, assim como as perdas com os insumos no processo produtivo são, via de regra, significativamente maiores e pouco analisadas, pelo menos de forma sistemática.

Uma ação gerencial eficaz passa pelo desenvolvimento e implantação de um sistema que consiga maximizar a relação benefício / custo da atividade de manutenção e operação para se identificar e quantificar das perdas, sendo útil para auxiliar o processo de análise e melhoria 
da eficiência interna dos processos produtivos, além da busca de oportunidades de melhoria que terão impacto no resultado operacional da empresa (NAKASATO, 1996)

Portanto, a obtenção de elevados padrões de qualidade e produtividade requer o tratamento adequado dos potenciais de melhoria de desempenho dos ativos industriais, onde se inserem:

- A avaliação sistematizada das perdas do processo produtivo;

- O cálculo do Índice de Eficiência Global (IEG) e a determinação dos gaps em relação a referenciais internos e externos de desempenho;

- O estabelecimento de referências internas e o cálculo para as outras perdas não consideradas no IEG;

- O direcionamento eficaz dos recursos disponíveis, uma vez identificadas as principais oportunidades de melhoria no processo produtivo.

Suzuki (1994) considera alguns dos princípios aplicados em empresas classificadas como "Classe Mundial" para a avaliação das principais perdas do processo de produção. No tocante à gestão de ativos industriais, significa perseguir continuamente a "Perda Zero" e o "Defeito Zero", através da eliminação de desperdícios, melhoria da qualidade e produtividade, além da busca pelo "Acidente Zero".

Nesse ambiente, Suzuki (1994) considera a ampliação do sentido da palavra "manutenção" que passa a ser relativa a todo o processo produtivo. Significa, portanto, manter a máxima produtividade, focalizando as perdas totais do processo e não apenas a integridade e confiabilidade dos ativos industriais.

Além disso, visando assegurar a sobrevivência das empresas num contexto de mercado globalizado, um papel adicional cabe à função da gestão das operações, qual seja, a de manter a máxima agilidade na identificação e implementação de melhorias.

Para Suzuki (1994), a empresa deve empregar o IEG como indicador de desempenho de um equipamento, linha de produção ou um sistema operacional em termos de disponibilidade, capacidade e qualidade, resultando numericamente no produto destes três fatores. É, portanto a relação entre o volume de produção especificado obtido e a máxima produção possível num determinado intervalo de tempo. As principais perdas do processo produtivo são expressas pelo IEG, conforme descrito a seguir.

- Perdas relativas a Paradas Programadas: Representam todas as perdas relacionadas aos tempos de paradas programadas de manutenção, bem como aqueles requeridos por requisitos operacionais (limpezas, etc.) e outros de natureza intrínseca ao processo produtivo, tal como a troca de catalisadores. 
- Perdas relativas a Ajustes de Produção: São os tempos perdidos correspondentes a ajustes no plano de produção devido a problemas de demanda ou elevação de estoques/inventário causados por fatores de mercado, e que de certa forma, não são totalmente controláveis pelas empresas. Entretanto o IEG pode ser incrementado através da manutenção de uma forte liderança de mercado em qualidade, custo, e tempo de fornecimento, além da busca de estímulo contínuo do mercado pelo desenvolvimento de novos produtos. Outros fatores externos tais como o suprimento de matérias-primas e/ou utilidades (falta de energia elétrica, por exemplo) são também aqui considerados como variáveis que têm impacto sobre o cálculo do IEG.

- Perdas relativas a Falhas de Equipamentos: Correspondem aos tempos perdidos quando a planta interrompe a produção de forma inesperada devido à ocorrência de falhas funcionais de determinados equipamentos. Falhas em bombas, queima de motores elétricos, mancais danificados, falhas de instrumentação de processo entre outros, são exemplos de causadores dessa natureza de perda.

- Perdas relativas a Falhas Operacionais: Correspondem aos tempos perdidos quando a planta interrompe a produção como resultado de fatores externos aos equipamentos, tais como erros operacionais ou mudanças nas propriedades físicas ou químicas das substâncias em processamento. Vazamentos, obstruções, entupimento de tubulações, sobrecarga dentre outros problemas são exemplos típicos de Falhas Operacionais.

- Perdas em Produção Normal: São perdas que ocorrem em operação normal relacionadas com a taxa de produção durante as paradas e partidas (warm-up/cool-down) e mudanças de especificação ou grades de produtos (set-up). A taxa de produção de referência em plantas de indústrias de processo usualmente não é atingida nos referidos períodos, eventos estes que devem ser tratados efetivamente como perdas.

- Perdas Relativas à Produção Anormal: São perdas relacionadas com a taxa de produção, e que ocorrem como resultado de mau funcionamento ou outras condições anormais, impedindo o cumprimento da taxa de produção de referência.

- Perdas Relativas à Produção Off-Spec / Rejeitos: Ocorrem quando da produção de produto fora de especificação (off-spec), produção de rejeitos e perdas financeiras pela venda de produto a preços inferiores devido ao não atingimento dos requisitos de qualidade estabelecidos pelos clientes.

- Perdas Relativas à Reprocessamento: Representam as perdas devido ao reciclo de produto fora de especificação e/ou rejeitos em etapas intermediárias do processo produtivo, 
visando o seu enquadramento na especificação requerida. Além das perdas diretas pela utilização de parte da capacidade produtiva da planta, o reprocessamento também representa perda de insumos, energia elétrica e demais utilidades, além de outros custos operacionais variáveis.

A Figura 2 ilustra a estruturação do conceito das principais perdas do IEG.

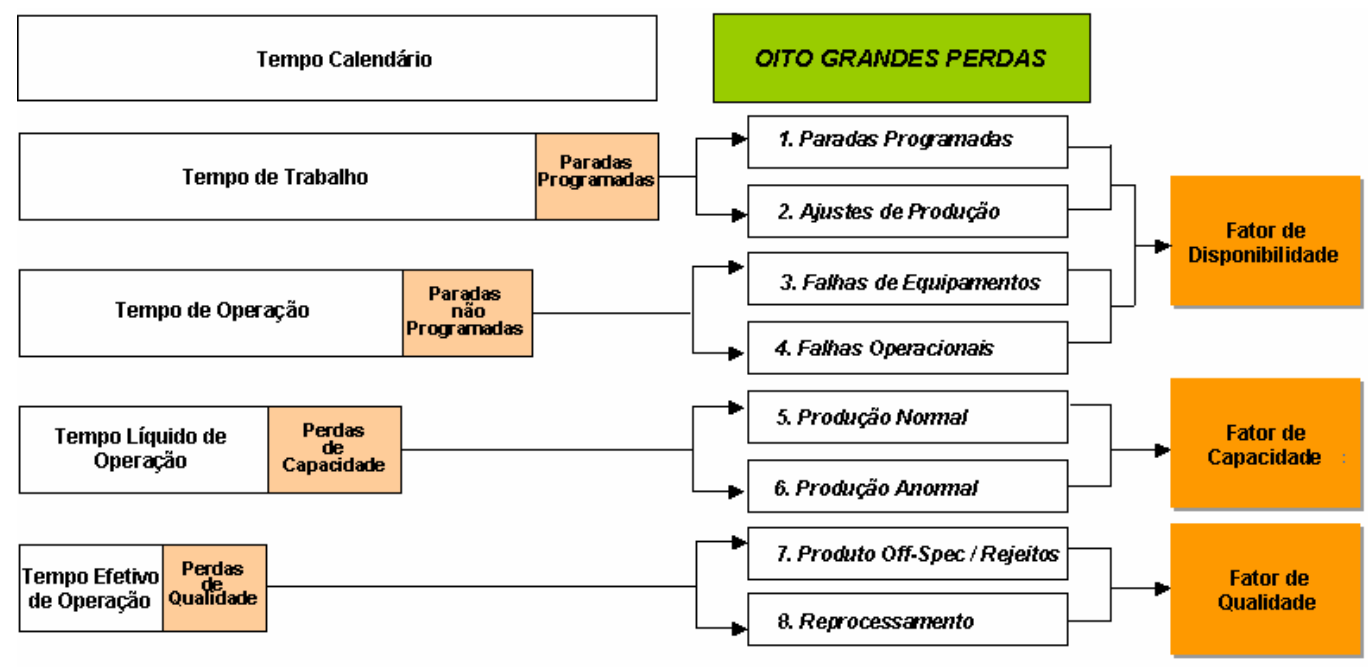

\section{OEE = Overall Equipment Effectiveness = Availability Factor $x$ Performance Rate $x$ Quality Rate}

IEG $=$ Indice de Eficiência Global $=$ Disponibilidade $x$ Desempenho $x$ Qualidade

Figura 2 - Estrutura dos tipos de perda para o cálculo do IEG (fonte: Takahashi e Osada, 1993, p 52)

Para obter os fatores e o respectivo Índice de eficiência Global de um ativo, pode-se acompanhar a seguinte seqüência:

a) $F D=T O / T C$

onde: $\mathrm{FD}=$ Fator de Disponibilidade $/ \mathrm{TO}=$ Tempo de operação e TC $=$ Tempo Calendário

b) $F C=T L O / T O$

onde: $\mathrm{FC}=$ Fator de Capacidade $/ \mathrm{TLO}=$ Tempo Líquido de operação e TC $=$ Tempo de Operação

c) $F Q=T E O / T L O$

onde: $\mathrm{FQ}=$ Fator de Qualidade $/$ TEO = Tempo Efetivo de Operação e TLO = Tempo Líquido de operação

d) $I E G=T E O / T C$ 
onde: $\mathrm{IEG}=$ Índice de Eficiência Global / TEO = Tempo Efetivo de Operação e TC = Tempo Calendário

Assim, para Sakaguchi (2001), o IEG representa um importante indicador para avaliar o quanto um ativo industrial está sendo utilizado de forma eficiente. Esse indicador, quando associado a aspectos econômicos, como a margem de contribuição do produto principal gerado pela planta industrial, fornece aos gestores fortes evidências das perdas econômicas ligadas quer seja a ineficiências da manutenção e operação, quer sejam ineficiências comerciais ou de suprimento. Com isso, ações estratégicas podem ser direcionadas para redução ou eliminação dessas perdas.

\section{METODOLOGIA}

\subsection{Enquadramento metodológico}

De acordo com o modelo para enquadramento metodológico proposto por Petri (2005), a pesquisa foi classificada como subjetivista, quanto à visão do conhecimento, como positivista, quanto ao paradigma científico, e como pesquisa particular, não-obstrusiva e pesquisa de campo, no que se refere à estratégia de pesquisa. Quanto ao método de pesquisa, é predominantemente quantitativa. Finalmente, quanto ao uso de instrumentos, trata-se de pesquisa documental. A base do trabalho constitui-se num estudo de caso para ilustrar a estruturação e a aplicação da árvore de perdas na realidade da indústria em referência para identificar e eliminar/reduzir desperdícios respectivamente.

\subsection{Hipótese a ser Verificada}

Hipótese nula (Ho): a implantação da árvore de perdas na empresa estudada não gerou resultados significantes no sentido de identificar e eliminar perdas no negócio,

Hipótese alternativa (Ha): os resultados obtidos pela implantação da árvore de perdas na empresa estudada são significantes. 


\subsection{Unidade de Estudo}

O recorte desta pesquisa deu-se numa unidade de negócios de uma empresa petroquímica localizada no pólo petroquímico de Camaçari, Bahia. Procedeu-se ao estudo basicamente através da avaliação do desempenho das capturas obtidas (redução das diferenças de desempenho em relação a referências estabelecidas), seu impacto em itens específicos como redução de custos variáveis, disponibilidade de ativos e aumento da capacidade de produção, dentre outros indicadores gerais ou específicos, dependendo dos casos analisados. A empresa, aqui identificada como Petroq1, é uma empresa petroquímica com matriz situada em São Paulo e 20 plantas industriais situadas nos estados do Rio Grande do Sul, Bahia, Alagoas e São Paulo. Com aproximadamente 2.200 integrantes diretos e 5.000 indiretos, está dividida em 3 unidades de negócio, 6 centros corporativos e tem faturamento anual na ordem de 600 milhões de dólares. Os processos produtivos englobam a primeira e a segunda gerações do ciclo produtivo petroquímico.

A figura 3 demonstra a estrutura organizacional da empresa Petroq1.

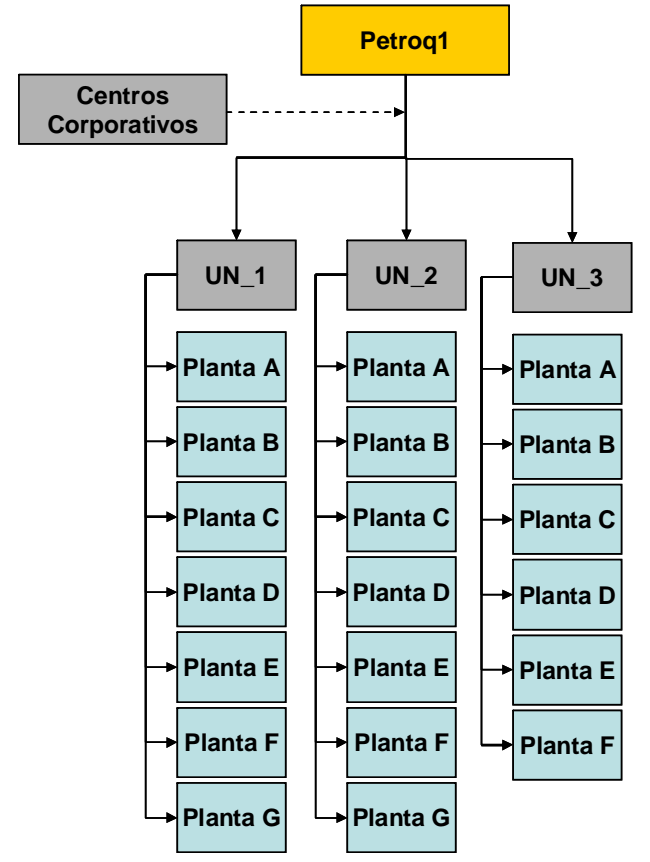

Figura 3 - Modelo estrutural da empresa estudada

A partir de 2002, essa empresa decidiu aplicar o modelo da Árvore de Perdas nas suas plantas como forma de identificar oportunidades de melhoria de performance em seus negócios, a partir da redução de produtos off-spec, melhoria de índices de consumo específico - o que tem impacto em custos variáveis - e na análise de fatores que tiveram influência na utilização da 
capacidade instalada de seus ativos. A unidade de negócios escolhida para realização deste estudo de caso é representante da segunda geração do processo petroquímico e possui 6 plantas distribuídas ao longo de 3 estados brasileiros. Ela representa aproximadamente $20 \%$ do resultado global da empresa e foi escolhida para este trabalho de pesquisa devido a forma estruturada e disciplinada como estruturou e implantou a sistemática.

\subsection{Coleta de Dados}

Foi realizada uma pesquisa documental referente a publicações de relatórios técnicos, material de circulação interna, apresentações e divulgações realizadas na intranet de uma das unidades de negócios de empresa escolhida. A unidade tomada por base neste trabalho foi escolhida pelo simples fato de ter os dados necessários à análise disponíveis e divulgados por toda a empresa. Além disso, havia dados disponíveis relativos aos anos de 2002 a 2004. Todos os valores econômico-financeiros apresentados neste trabalho levaram em consideração o ano de 2002, ou seja, a base monetária permaneceu congelada nos anos posteriores a 2002, para se isolarem os efeitos relacionados à variação de preços e margens. Os principais dados levantados foram: histórico de implantação do modelo da árvore de perdas; principais definições de conceito utilizadas na estruturação da árvore de perdas; tabelas de classificação de perdas elaborada pela empresa; princípio utilizado para cálculo das perdas; estruturação conceitual da composição das perdas; valores de perdas encontrados a partir da aplicação do modelo da árvore de perdas e estratificação pode planta industrial dos grupos de perda.

\section{IMPLANTAÇÃO DA ÁRVORE DE PERDAS}

\subsection{Procedimento para estruturação da árvore de perdas}

O procedimento adotado pode ser expresso a partir do fluxo demonstrado na figura 4. 


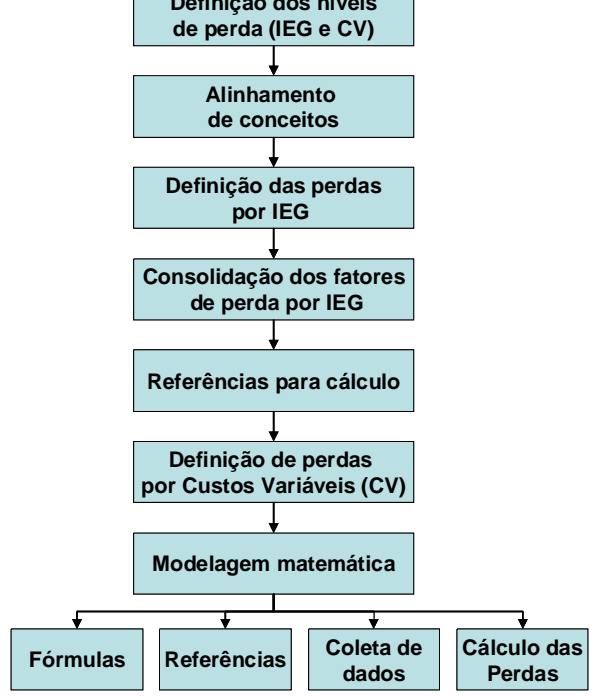

Figura 4 - Fluxo do procedimento adotado na implantação da árvore de perdas

\subsubsection{Definição dos níveis de perda}

O passo inicial da concepção do modelo que teve por base a utilização daquele proposto por Suzuki (1994), consistiu na definição dos principais níveis da árvore. Um grupo composto por representantes das áreas de Produção, Manutenção e Planejamento Industrial, em cada planta, ficou incumbido de definir, em conjunto com a área corporativa de Qualidade e Produtividade, os itens que comporiam a estrutura da árvore. Esse grupo definiu que na fase I do projeto seriam avaliados o IEG e os custos variáveis, dado que o IEG foi identificado como um dos pontos importantes para se analisarem as perdas por não utilização da capacidade do ativo e pelo fato dos custos variáveis serem responsáveis por, em média, $80 \%$ dos custos totais dos produtos. Um outro fator contribuiu para esta decisão: dado o prazo (quatro meses) definido para estruturação e análise do primeiro ano, uma estrutura com maior complexidade ou com a necessidade de se estabelecer referências ainda não estudadas - como o caso de logística - poderiam comprometer o prazo e a qualidade dos resultados gerados pelo modelo.

\subsubsection{Alinhamento de conceitos}

O segundo passo do trabalho consistiu do alinhamento dos conceitos utilizados no modelo. $\mathrm{O}$ objetivo desta fase foi o de ter a mesma compreensão dos termos utilizados e dos princípios de cálculo. Com isso, garantiu-se que a terminologia e o método de cálculo fossem os 
mesmos, independentemente da planta ou local geográfico onde a árvore estivesse sendo aplicada. A seguir, apresentam-se alguns dos termos utilizados, segundo o alinhamento geral realizado entre os conceitos do TPM e a prática da empresa.

Capacidade Instalada: taxa de produção instantânea da unidade / planta / equipamento. Pode ser definida em base horária ou diária. Ex: t/h, t/dia;

Capacidade Nominal: taxa instantânea de produção registrada na documentação de projeto, acumulada nos 365 dias ou nas 8760 horas do ano, conforme a base escolhida (horária ou diária). Na capacidade nominal NÃO se deve considerar fatores operacionais.

Capacidade da Campanha: quantidade média produzida no período da campanha da unidade na capacidade nominal considerando-se o tempo de parada. ex.: Se a campanha de uma unidade for de 5 anos, a capacidade nominal for 50.000 toneladas por mês e o tempo de parada for de 1 mês, a capacidade da campanha será de $(50.000 \times 59) / 60=49.167 \mathrm{t} /$ mês.

Capacidade Máxima Anual: máximo da produção instantânea da unidade x 8760 horas ou 365 dias, conforme a base escolhida (horária ou diária). O máximo de produção a ser considerado pode ser obtido a partir de:

- testes de capacidade;

- capacidade nominal, caso não se conheça o limite da unidade ou caso a capacidade nominal não tenha sido ultrapassada;

- recorde de produção atingido de forma consistente. Como consistente entenda-se:

- Variáveis críticas de processo estáveis;

- condições de Saúde, Segurança e Meio Ambiente (SSMA) atendidas;

- qualidade do produto mantida;

- condição dos equipamentos sem degradação.

Nos casos das plantas de polímeros, onde o grau a ser produzido afeta a taxa de produção da unidade, deve-se considerar o "mix" de produção típico em relação ao propósito da planta versus a margem de contribuição média.

Capacidade Máxima Anual Benchmark: Capacidade Máxima Anual multiplicada pelo máximo de utilização da capacidade da planta de melhor performance. Nesta capacidade já estão incluídos: fator de operação, trocas de grade, qualidade de matéria-prima, etc. O propósito desse índice é comparar qual seria a utilização de capacidade de uma planta de 
alta performance se tivesse um ativo com a capacidade máxima anual igual a que está em estudo.

\subsubsection{Definição das perdas por índice de eficiência global}

O terceiro passo consistiu nas definições de perda por IEG. Nesta etapa foram conceituados, utilizando-se por base os conceitos do modelo de Suzuki (1994), os três tipos de perda adotados pelo modelo da empresa em estudo.

Perdas por Indisponibilidade: é considerada perda por indisponibilidade toda vez em que não haja produção, ou seja, toda vez em que o produto principal da unidade não seja produzido por parada da planta. A sua quantificação é feita tomando-se por base a quantidade de horas da planta parada vezes capacidade máxima vezes a margem de contribuição unitária anual média.

$>$ Perdas por Redução de Capacidade: é toda vez que a produção máxima da unidade não é atingida. Sua quantificação é feita considerando-se a diferença entre a quantidade real produzida e o máximo de capacidade da unidade x o tempo em que a unidade ficou com carga reduzida x a margem de contribuição unitária anual média.

Perdas por Produto Fora de Especificação (off spec): É toda vez que a capacidade e outros recursos da unidade foram utilizados para produzir off spec. É quantificada pela quantidade de produtos fora de especificação vezes a diferença de preço entre o produto prêmio e o produto off spec.

Índice de Eficiência Global (IEG): é a diferença existente entre o máximo que a unidade produziria no ano (capacidade máxima anual) e o real on spec produzido. Sua quantificação é o somatório das perdas por indisponibilidade, por redução de capacidade e por produção off spec. 


\subsubsection{Consolidação dos fatores de perda por índice de eficiência global}

Na quarta etapa, buscou-se consolidar todos os possíveis fatores que pudessem levar à perda do IEG em cada um dos três tipos de perdas. O objetivo desta estratificação tem por base a maior facilidade de analisarem-se as causas das perdas e de ser possível focalizar as ações para sua eliminação ou redução. Os quadros 1, 2 e 3 identificam os principais fatores por perda.

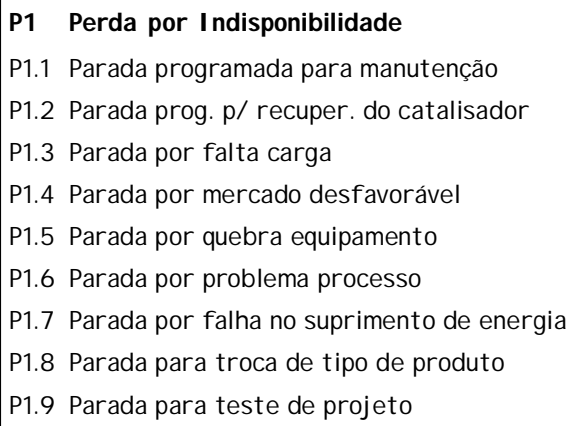

Quadro 1 - Fatores de perda por indisponibilidade (fonte: empresa Petroq1)

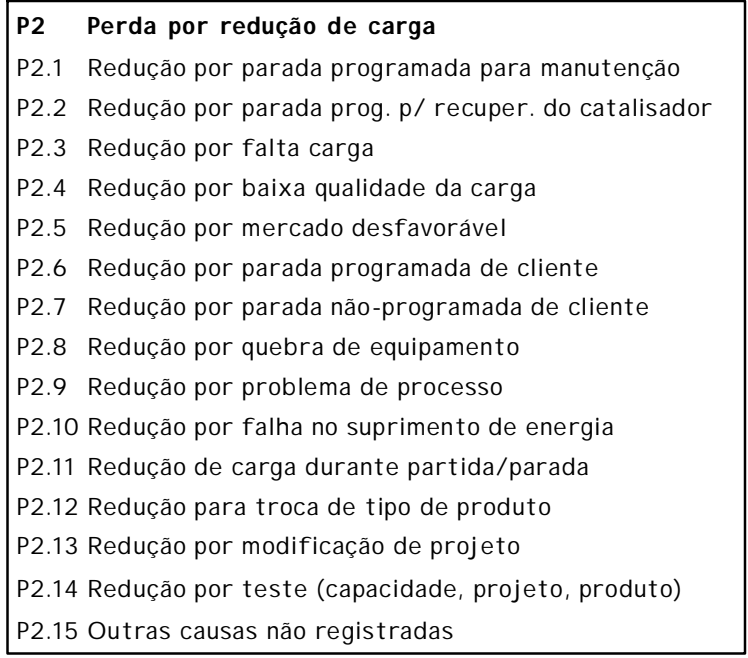

Quadro 2 - Fatores de perda por redução da capacidade (fonte: empresa Petroq1)

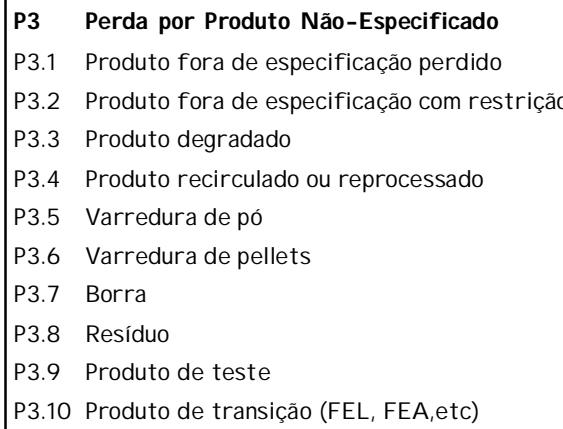




\section{Quadro 3 - Fatores de perda por produto fora de especificação (fonte: empresa Petroq1)}

\subsubsection{Referências para cálculo}

$\mathrm{Na}$ quinta etapa do processo definiram-se os estágios para considerar os cálculos de perda. Esta definição é o que indica que referências são utilizadas para o cálculo. Sendo assim, a empresa definiu três possíveis níveis de referências a serem aplicadas com as suas respectivas utilizações. A simplificação destas definições está exposta na figura 5.

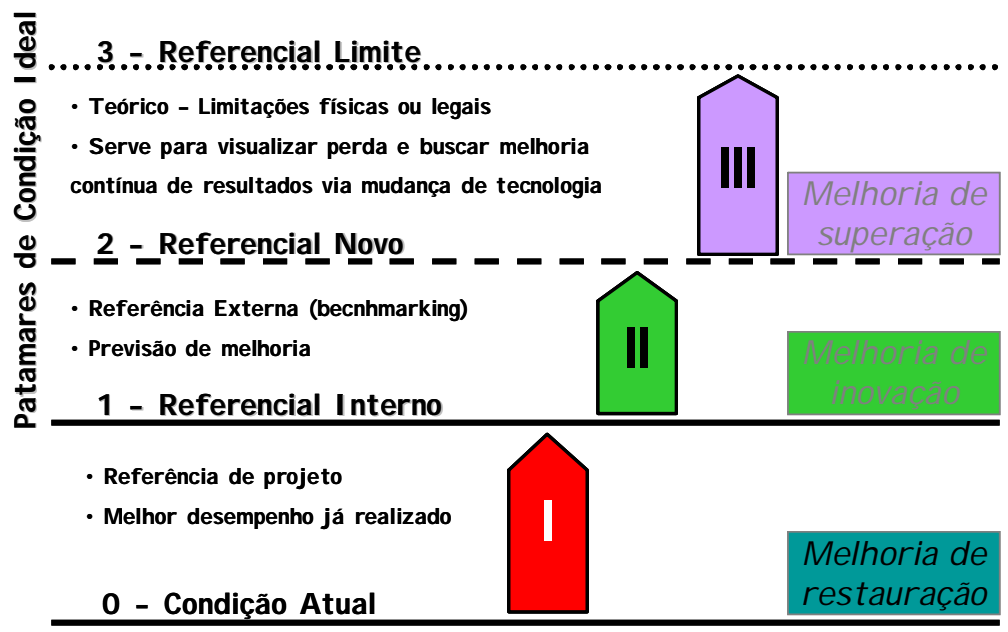

Figura 5 - Modelo de cálculo de perdas adotado pela empresa (fonte: empresa Petroq1)

\subsubsection{Definição das perdas por custos variáveis}

Na Sexta fase do projeto definiu-se o modelo de cálculo dos custos variáveis seguindo os conceitos alinhados e definidos pelo grupo. Nessa fase, o grupo definiu a seguinte fórmula de cálculo para apurar os gaps em CV:

$\mathrm{Gap}_{\mathrm{CV}}=\quad($ índice real - índice referência $) *$ volume real produzido $*$ Preço do insumo

Uma vez definida a forma de cálculo, foi necessário definir as categorias de perda para custos variáveis as quais foram agrupados em 5 classes e 12 gêneros. O resultado final desta classificação pode ser visualizado no quadro 4 . 
ISSN 1676 - $1901 /$ Vol. 7/ Num. 2/ agosto 2007

\begin{tabular}{|c|c|c|c|c|c|c|c|c|c|c|c|c|}
\hline Perda & $P 1 \cdot P 2 \cdot P 3$ & $\mathscr{P} 4$ & $P 5$ & & $P 6$ & & $P 7$ & $P \mathcal{P}$ & $p 9$ & $P 10$ & $P 11$ & $P 12$ \\
\hline Gêner & $\begin{array}{l}\text { Produto } \\
\text { Principal }\end{array}$ & $\begin{array}{l}\text { Matérias. } \\
\text { Primas }\end{array}$ & $\begin{array}{c}\text { Crédito } \\
\text { Produzido }\end{array}$ & Energéticos & $\begin{array}{c}\text { Crédito } \\
\text { Energético }\end{array}$ & $\begin{array}{c}\text { Débito } \\
\text { Energético }\end{array}$ & $\begin{array}{l}\text { Insumos } \\
\text { Ultilidades }\end{array}$ & $\begin{array}{c}\text { Outras } \\
\text { Utilidades }\end{array}$ & $\begin{array}{l}\text { Outros } \\
\text { Insumos }\end{array}$ & $\mid \begin{array}{c}\text { Outros } \\
\text { Créditos }\end{array}$ & $\begin{array}{c}\text { Correntes } \\
\text { parao } \\
\text { Ambiente }\end{array}$ & Emb a lage ns \\
\hline 1 & $\begin{array}{c}\text { Produto } \\
\text { Principal } \\
\quad(P P)\end{array}$ & $\begin{array}{l}\mathcal{N} \text { (afta } \\
(\mathfrak{N O}\end{array}$ & $\begin{array}{c}\text { Corrente } \\
\text { Intermediária } \\
\text { Produzida } \\
\text { (CIP) }\end{array}$ & $\begin{array}{c}\text { Energia } \\
\text { Elétrica } \\
\text { (EE) }\end{array}$ & $\begin{array}{c}\text { Cré dito } \mathcal{E E} \\
(\text { CEE })\end{array}$ & $\begin{array}{c}\text { Dé } 6 \text { ito EE } \\
\text { (DDEE) }\end{array}$ & $\begin{array}{c}\text { Comb us tive is } \\
\text { Adquiridos } \\
\text { (CA) }\end{array}$ & $\begin{array}{c}\text { Águas } \\
\text { Consumidas } \\
\text { (CW) }\end{array}$ & $\begin{array}{l}\text { Produtos } \\
\text { Químicos } \\
\quad(P Q)\end{array}$ & $\begin{array}{c}S u b . \\
\text { Produtos } \\
(S u \mathcal{P})\end{array}$ & 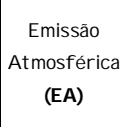 & $\begin{array}{c}\text { Embalage m } \\
\text { Exportação } \\
\text { (EMMBX) }\end{array}$ \\
\hline 2 & $\begin{array}{c}\text { Produto } \\
\text { Principal } \\
\text { off } \\
(\mathscr{P P})\end{array}$ & $\begin{array}{c}\text { Outras } \\
\text { Matérias. } \\
\text { Primas } \\
\text { (OMP) }\end{array}$ & $\begin{array}{c}\text { Coprodutos } \\
(\operatorname{CoP})\end{array}$ & $\begin{array}{c}\text { Vapor } \\
(\mathcal{V})\end{array}$ & $\begin{array}{l}\text { Crédito } \\
\text { Vapor } \\
\text { (CRV) }\end{array}$ & $\begin{array}{l}\text { Débito } \\
\text { Vapor } \\
\text { (DRR) }\end{array}$ & $\begin{array}{c}\text { Águas } \mathcal{B} r \text { utas } \\
(\mathcal{B} W)\end{array}$ & $\begin{array}{c}\text { Gases } \\
\text { Industriais } \\
\text { (GIC) }\end{array}$ & $\begin{array}{c}\text { Solventes } \\
(\mathrm{S} \text { ol })\end{array}$ & & $\begin{array}{l}\text { Água do } \\
\text { Effuente } \\
\text { Orgânico } \\
\text { (AEO) }\end{array}$ & $\begin{array}{c}\text { Embalage m } \\
\text { Mercado } \\
\text { Nacional } \\
\text { (EMMBN) }\end{array}$ \\
\hline 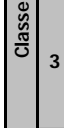 & & $\begin{array}{c}\text { Corrente } \\
\text { Intermediária } \\
\text { Consumida } \\
\text { (CIC) }\end{array}$ & $\begin{array}{l}\text { Combustive is } \\
\text { Produzidos } \\
\text { (CP) }\end{array}$ & $\begin{array}{c}\text { Combustive is } \\
\text { Consumidos } \\
\text { (CC) }\end{array}$ & & & $\begin{array}{c}\text { Energia } \\
\text { Elétrica } \\
\text { Adquirida } \\
\text { (EEA) }\end{array}$ & & $\begin{array}{c}\text { Catalisadores } \\
\text { (Cat) }\end{array}$ & & $\begin{array}{c}\text { Carga } \\
\text { Orgânica do } \\
\text { Effuente } \\
\text { (COE) }\end{array}$ & \\
\hline 4 & & $\begin{array}{c}\text { Catalisador } \\
\text { Co-catalisador } \\
\text { (CCC) }\end{array}$ & & & & & $\begin{array}{c}\text { Gases } \\
\text { Adquiridos } \\
\text { (GIA) }\end{array}$ & & $\begin{array}{c}\text { Serviços } \\
\text { Tratamento } \\
(S \mathcal{T})\end{array}$ & & $\begin{array}{c}\text { Ef fuente } \\
\text { Inorgânico } \\
\text { (EI) }\end{array}$ & \\
\hline 5 & & $\begin{array}{c}\mathcal{A} d \text { ditivos } \\
(\mathfrak{A D I})\end{array}$ & & & & & & & & & $\begin{array}{c}\text { Resíduo } \\
\text { Sólido } \\
\text { (RS) }\end{array}$ & \\
\hline
\end{tabular}

Quadro 4 - Classificação dos tipos de perda em custos variáveis (fonte: empresa Petroq1)

\subsubsection{Modelagem matemática}

O modelo estruturado para a análise das perdas da empresa em estudo pode ser conferido nas figuras 6,7 e 8 .

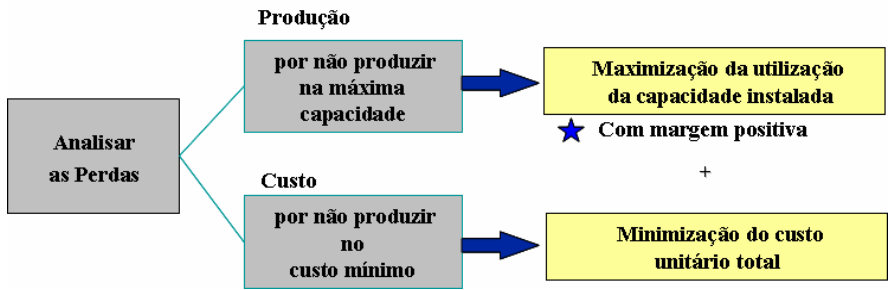

Figura 6 - Princípio utilizado para cálculo das perdas (fonte: empresa Petroq1)

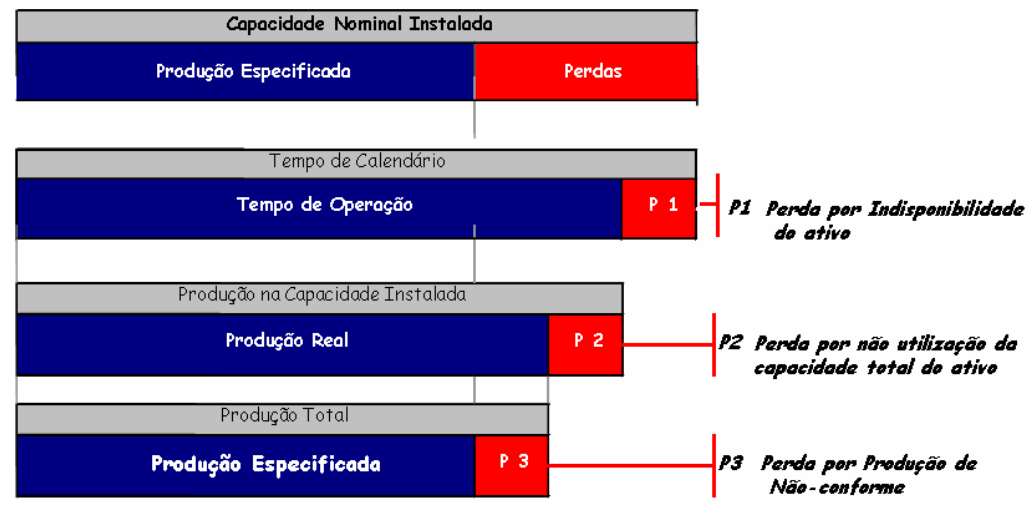

Figura 7 - Estruturação conceitual da composição das perdas por IEG (fonte: empresa Petroq1) 


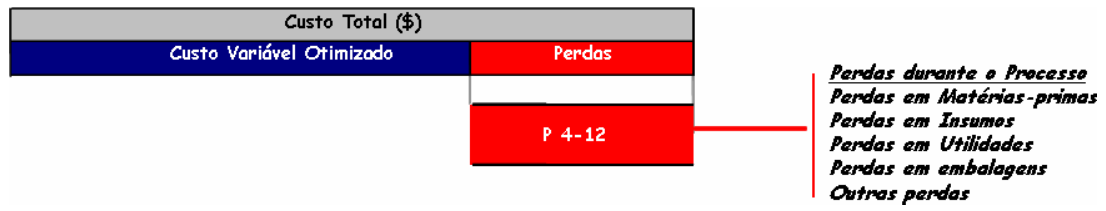

Figura 8 - Estruturação conceitual das perdas em CV (fonte: empresa Petroq1)

As últimas fases do processo de estruturação do modelo consistiram da modelagem matemática em planilhas Excel, do levantamento das referências nível 1, ou seja, referências de projeto ou melhores marcas já alcançadas de forma consistente - o que fosse maior (no caso do IEG) ou menor (no caso do CV). Por fim, o levantamento dos dados do ano anterior, 2002 e o cálculo propriamente do volume das perdas utilizando o modelo.

\subsection{Levantamento das perdas}

Os dados apresentados a seguir são referentes ao levantamento das perdas de uma das unidades de negócio da empresa Petroq1, em estudo. Os números a serem apresentados demonstraram uma proporcionalidade com os números reais obtidos nos estudo, mas não divulgados na sua íntegra por serem estratégicos para a empresa.

No início da análise das perdas, algumas premissas e objetivos foram estabelecidos e comunicados a todas as equipes envolvidas no trabalho. Os mais importantes estão listados a seguir:

- O estudo procurou manter as mesmas premissas utilizadas no primeiro levantamento (diagnóstico Petroq1 2002), mantendo os preços e as margens do primeiro ano de referência para efeito de comparação. Ele teve como principais objetivos:

- Identificar e analisar as oportunidades existentes em relação à utilização da capacidade máxima das plantas (IEG) e desempenho dos índices técnicos dos custos variáveis.

- Analisar a evolução da recuperação das oportunidades ano a ano, motivando a "aceleração" de ações que agregaram valor ao negócio e focando os pontos que mereceram maior atenção.

- Servir como ponto de partida para:

- Implantação do Sistema de Produção da Empresa.

- Planejamento para a recuperação das perdas apresentadas, no horizonte 20032007.

- Identificação de desafios para os ciclos de planejamento estratégico. 
A base de preços adotada foi congelada e mantida constante em todos os anos subseqüentes visando manter a base monetária de comparação constante e, com isso, isolar os efeitos de preço, focalizando nos aspectos operacionais que pudessem afetar diretamente a eficiência do processo produtivo da empresa.

Após estabelecidas as premissas e objetivos do trabalho, os dados foram levantados e inseridos no modelo. Tanto os dados referentes ao realizado no ano quanto as referências internas foram discutidos com as equipes de produção, engenharia, planejamento, finanças e qualidade e produtividade. Os dados validados foram inseridos no modelo e os resultados analisados sob a ótica dos eventos ocorridos e históricos registrados nos documentos da empresa.

O resultado do modelo aplicado a uma das plantas da unidade de negócios mostrou um volume de perdas considerado pelos gestores da planta e da Unidade como sendo uma "oportunidade" para direcionar ações especificas para eliminar os gaps mais importantes para aquela planta em particular. No caso específico desta planta industrial, as oportunidades se concentraram mais fortemente no IEG. Ao se analisar a unidade de negócios como um todo, pôde-se perceber não só os principais focos de oportunidade, como também a influência efetiva que determinadas plantas têm no resultado como um todo. Os resultados do modelo para a planta em estudo e para a Unidade, considerando o somatório de todas as plantas daquela Unidade de Negócios (UN3) encontram-se nas figuras 10 e 11.

Após o levantamento inicial, também foram calculados os IEG's de cada uma das plantas industriais e da Unidade de Negócios como um todo. Estas informações estão representadas na figura 12. Os índices foram calculados pelo produto entre os três fatores: FD, FC e FQ - ou seja, Fator de Disponibilidade, Fator de Capacidade e Fator de Qualidade.

Nesta análise preliminar não foi feita a normalização ou qualquer tratamento adicional em termos de tamanho das plantas ou idade tecnológica. Entretanto, o objetivo inicial não estava centrado em análises de benchmark, mas em ações locais a serem tomadas por cada uma das plantas para melhorar a utilização dos ativos industriais. 


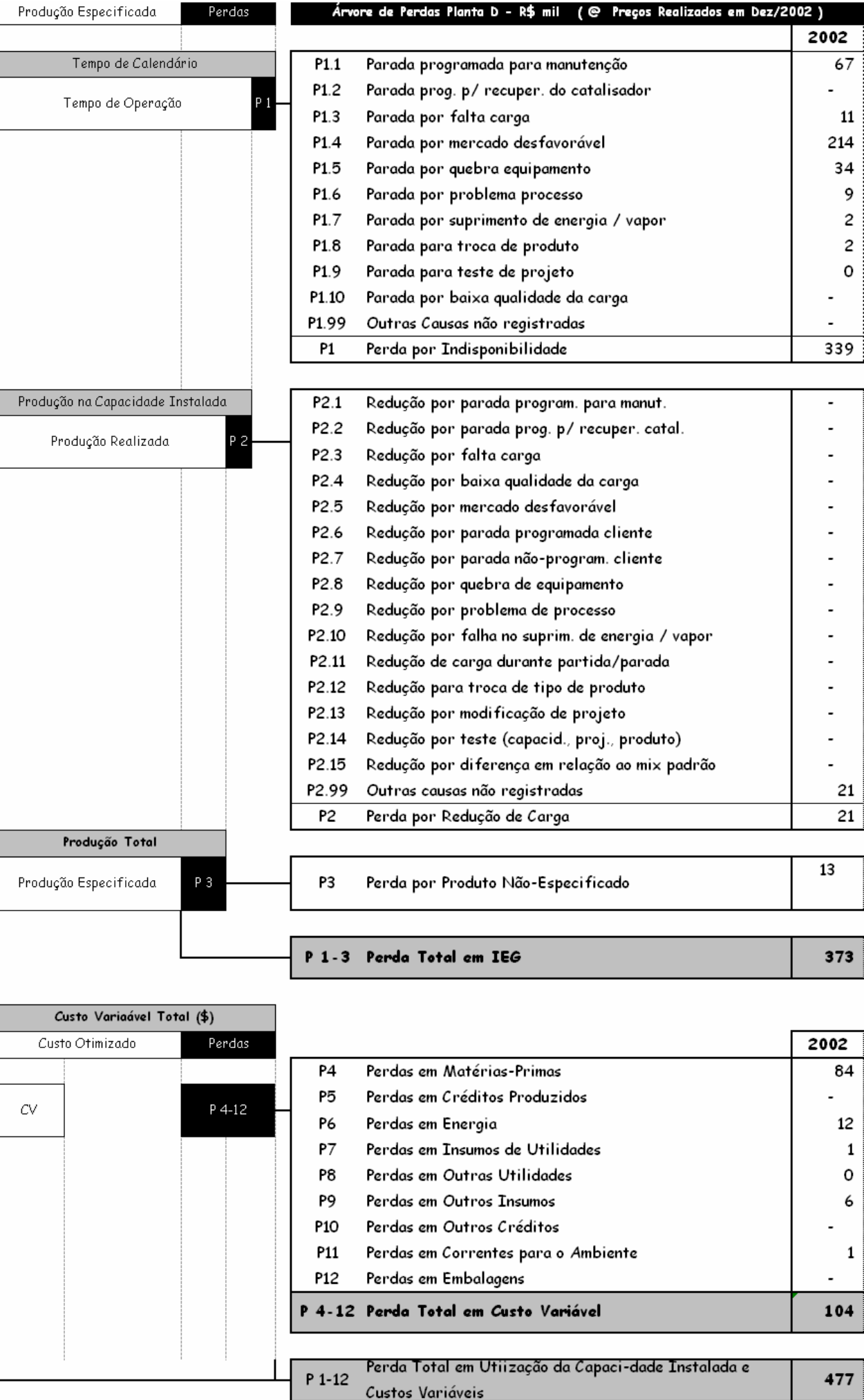

Figura 10 - Resultado do modelo matemático da árvore de perdas aplicado à planta $\mathrm{D}$ (fonte: empresa Petroq1) 


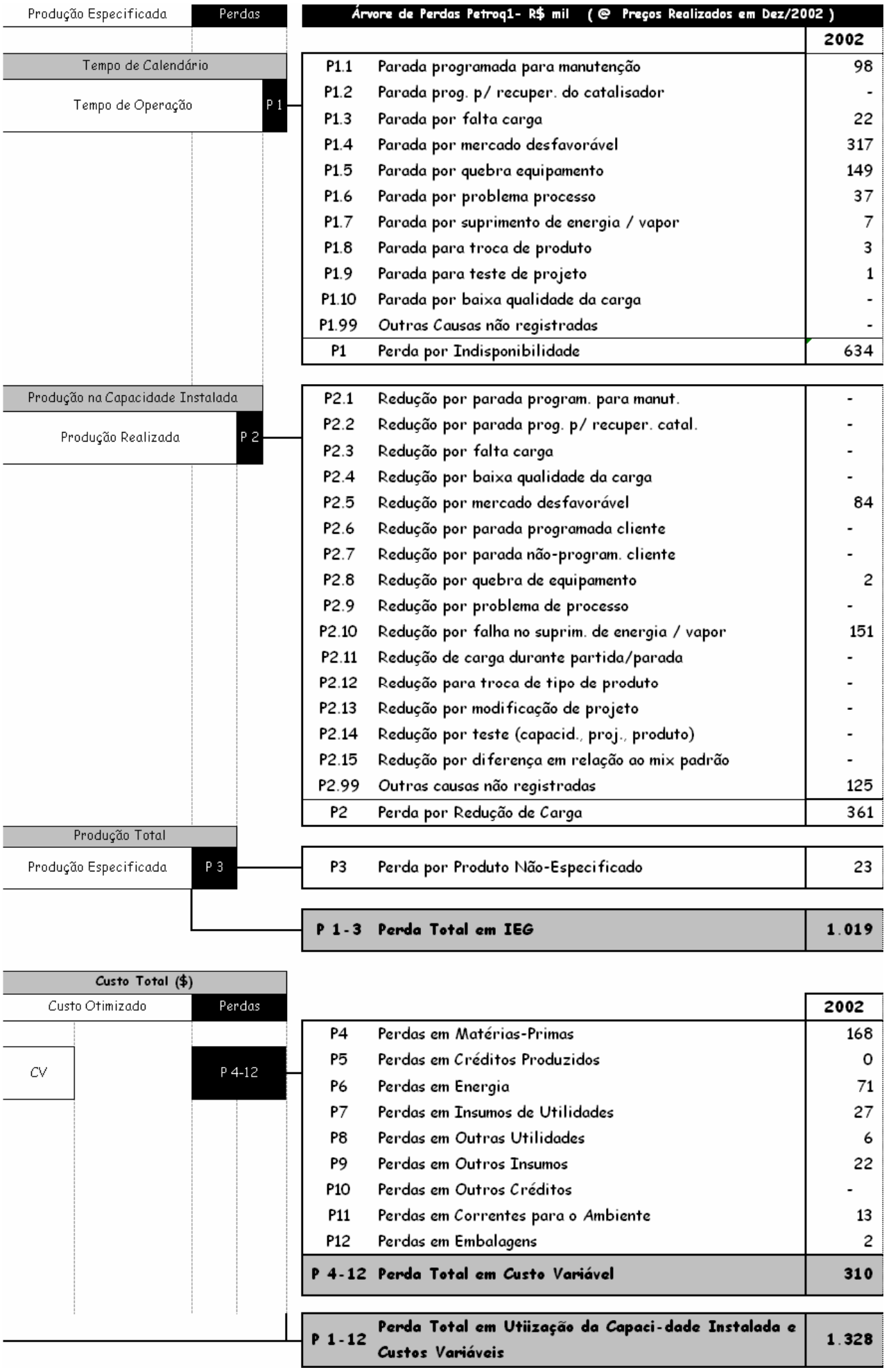

Figura 11 - Resultado do modelo matemático da árvore de perdas aplicado à UN 3 (fonte: empresa Petroq1) 
IEG das Plantas (UN) - 2002)

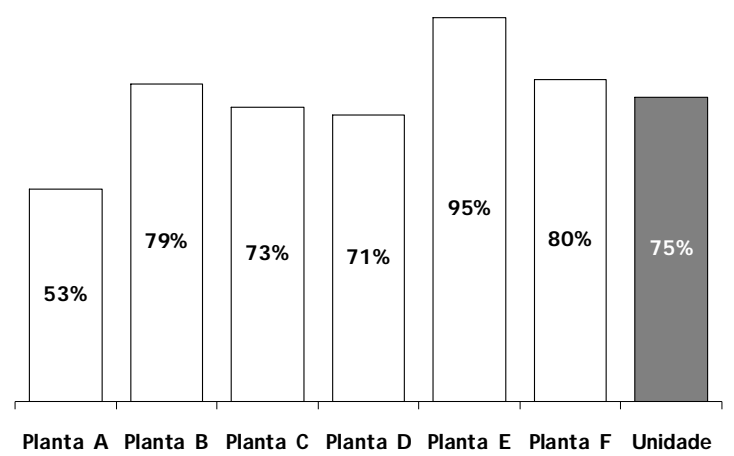

Figura 12 - IEG das Plantas da UN3 (fonte: empresa Petroq1)

\subsection{Redução das Perdas}

A partir do levantamento das perdas, cada planta industrial da empresa desenvolveu um plano de ação que foi contemplado no planejamento estratégico com o objetivo de reduzir as suas perdas. As principais ações sob a responsabilidade da área industrial da empresa estavam relacionadas ao aumento do IEG, aumentando a disponibilidade e utilização da capacidade das plantas e a melhoria de eficiência dos índices de consumo, o que gera impacto nos custos variáveis. O resultado do plano de ação da UN3 encontra-se representado na figura13.

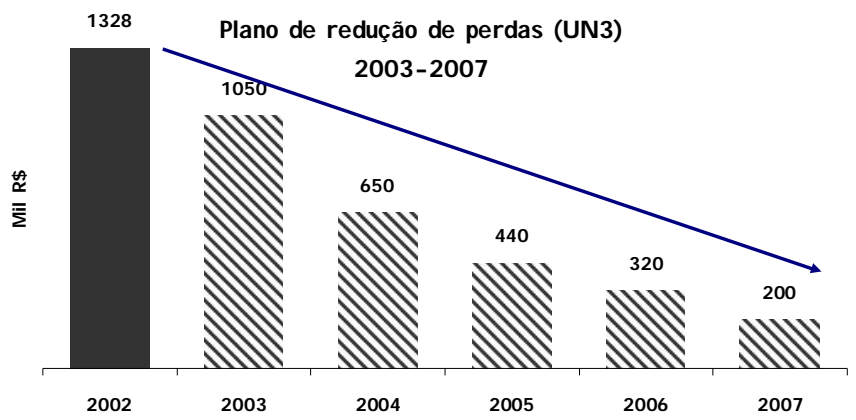

Figura 13 - Plano de redução de perdas para a UN 3 (fonte: empresa Petroq1)

A mensuração dos resultados através dos anos subseqüentes ao ano de 2002 mostrou o valor da aplicação de uma estrutura de análise e interpretação de resultados e o direcionamento de ações alinhadas ao objetivo do negócio. Como pode ser observado na figura 14, as 4 principais perdas identificadas na UN3 foram sendo consistentemente eliminadas. 


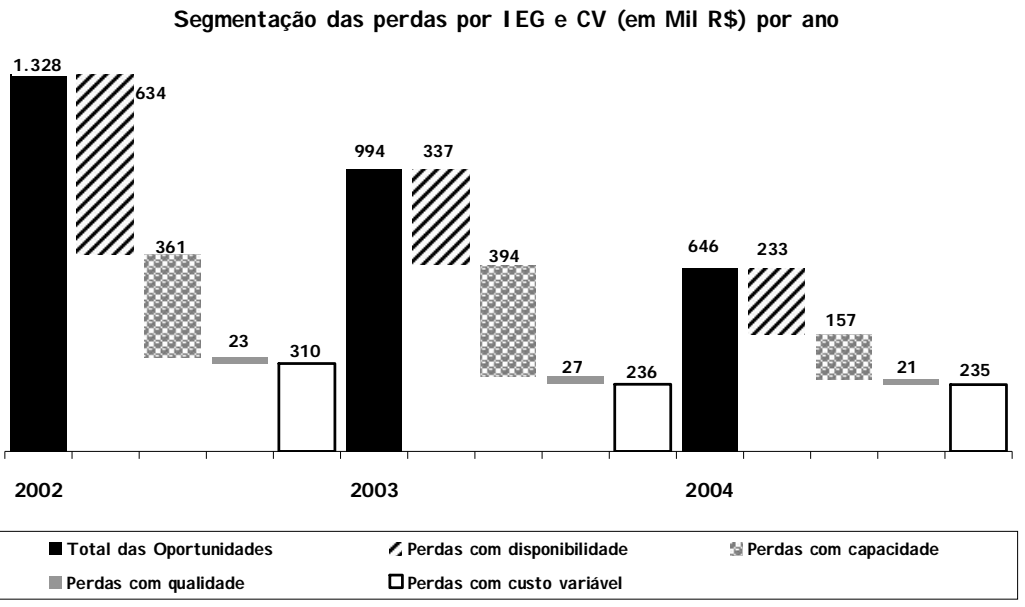

Figura 14 - Análise da árvore de perdas na UN3 nos anos 2002-2004 (fonte: empresa Petroq1)

Da mesma forma, foram mensurados os resultados de IEG das plantas ao longo dos anos. A figura 15 demonstra que, com exceção da planta $\mathrm{F}$, todas as demais plantas tiveram aumento da utilização de seus ativos. Como resultado, a UN3 teve um aumento de utilização dos seus ativos.

IEG das plantas (\%) 2002 a 2004

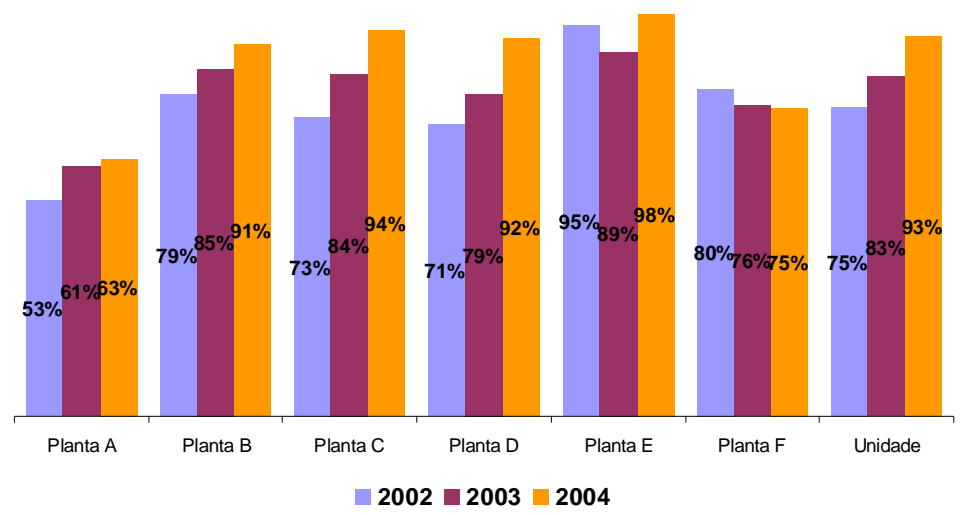

Figura 15 - IEGs das plantas da UN3 entre 2002 e 2004 (fonte: empresa Petroq1)

Pela análise dos resultados apresentados, pode-se verificar que ações foram tomadas no sentido de melhorar o Índice de Eficiência Global (IEG), principalmente relacionado ao aumento da disponibilidade dos ativos no primeiro ano. No ano seguinte (2004), as ações foram mais imperativas no sentido de se buscar utilizar de maneira mais eficiente a capacidade dos ativos. Também as ações relacionadas a fatores externos tiveram um impacto considerado positivo na redução do volume de perdas. 
Por fim, uma consolidação foi realizada no sentido de se observar a aderência entre o plano de recuperação das perdas proposto no primeiro ano do trabalho e os resultados obtidos ao longo dos anos de sua utilização como referência para tomada e priorização de ações. A figura 16 mostra as perdas identificadas e aquelas previstas a partir do planejamento realizado pela UN3.

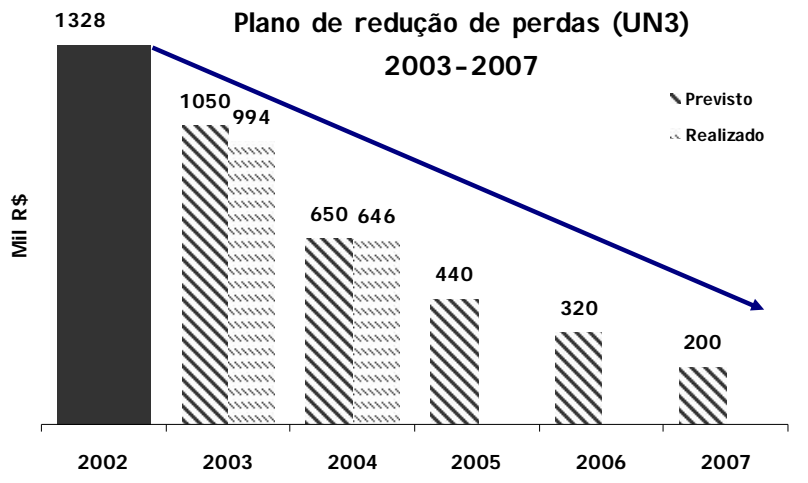

Figura 16 - Plano de redução de perdas da UN3 - Previsto versus realizado (fonte: empresa Petroq1)

A partir da análise gráfica da figura 17, é possível identificar que a empresa definiu uma taxa de redução de aproximadamente $20 \%$ no primeiro ano e $40 \%$ no segundo ano, bem como que os resultados obtidos pela empresa, através da aplicação conjunta das sistemáticas, indicaram uma superação de aproximadamente $6 \%$ em relação ao planejado no primeiro ano e de aproximadamente $1 \%$ em relação ao segundo ano.

\subsection{Análise da hipótese de pesquisa}

Para se testar a hipótese nula de que a implantação da árvore de perdas na empresa estudada não gerou resultados significantes no sentido de identificar e eliminar perdas no negócio, considerou-se uma abordagem quantitativa e outra, qualitativa.

$\mathrm{Na}$ abordagem quantitativa, observou-se que as ações adotadas na aplicação da sistemática geraram reduções nas perdas na ordem de $R \$ 334.000,00$ no primeiro ano e $R \$ 348.000,00$ no segundo ano. Considerando uma amostra aleatória simples, tais resultados permitem inferir que a redução média nas perdas é maior do que $\mathrm{R} \$ 296.800,00$, com $95 \%$ de confiança. Aplicando-se o teste t de Student para uma média simples, obtém-se uma estatística t=48,7, a qual conduz a uma probabilidade de significância de 0,0065. Considerando-se um teste unilateral ( $\left.\mathrm{t}_{\text {crítico,5\%,1gl }}=6,314\right)$, rejeita-se a hipótese nula com $1 \%$ de significância. Isto permite 
afirmar que o resultado é significante, ou seja, que a implantação da árvore de perdas na empresa estudada gerou resultados significantes no sentido de identificar e eliminar as perdas.

Da mesma forma, os IEGs da UN3 foram 75\%, 83\% e 93\% em 2002, 2003 e 2004, respectivamente. Analisando-se os incrementos nos níveis de IEG atingidos pela UN3 pode-se observar um acréscimo de 8\% em 2003 e 10\% em 2004. Considerando-se uma amostra aleatória simples, estes resultados permitem inferir que o incremento de IEG médio da UN3 é maior do que $2,7 \%$, com $95 \%$ de confiança. O teste $\mathrm{t}$ de Student para uma média simples aponta para uma estatística $t=9$ (probabilidade de significância de 0,035). Em um teste

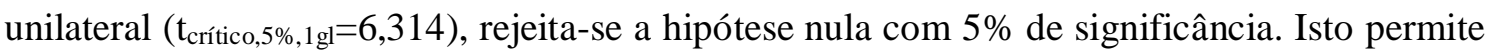
afirmar que o resultado obtido é significante, ou seja, que a implantação da árvore de perdas na empresa estudada gerou resultados significantes no sentido de aumentar o Índice de Eficiência Global da UN3.

$\mathrm{Na}$ abordagem qualitativa, foi considerado que as perdas identificadas a partir da sistemática da Árvore de Perdas foram reduzidas consistentemente ao longo dos anos 2002, 2003 e 2004, tanto considerando o IEG quanto o Custo Variável. Finalmente, o plano de redução das perdas atingiu e até superou os objetivos originais. Por isso, entende-se que é possível rejeitar a hipótese nula levantada na seção 3.2 e, portanto, conclui-se que a hipótese alternativa seja verdadeira.

\subsection{Restrições da análise}

Alguns casos de restrição ou alguns cuidados a serem tomados foram identificados nos processos de análise das perdas. Um deles diz respeito à correlação ou interferência que determinadas categorias de perda podem ter entre elas. Um caso típico refere-se a determinados índices de consumo específico, notadamente aqueles referentes a consumo energético, têm com o IEG. Abaixo de $85 \%$ de utilização de capacidade, estes coeficientes podem afetar negativamente o $\mathrm{CV}$ e podem mascarar a análise das ações a serem tomadas para eliminação das perdas. Em outras palavras, é importante se avaliar com os grupos de tecnologia e engenharia de processo a influência dos elementos componentes dos custos variáveis com o IEG, para se evitar a tomada de ações que podem ser infrutíferas caso não se defina, inicialmente a elevação deste prioritariamente em relação ao CV.

Um outro caso crítico pode estar relacionado a programação de paradas para manutenção programada. Notadamente esta indústria é marcada por períodos de operação contínua, 
denominada de campanha, e por necessidade de intervenção em grandes manutenções periódicas, normalmente em intervalos de 3 anos, que têm duração entre 20 e 30 dias naquele ano. A perda do histórico de manutenção pode mascarar as ações no sentido de poder concluir, erroneamente, que, naquele ano, as perdas por disponibilidade foram excessivamente elevadas e que, portanto, algo pode ter saído errado. Neste caso, seria recomendado que ações fossem tomadas no sentido de tornar o processo de manutenção o mais produtivo possível, visando reduzir o período de shutdown, em que a planta industrial fica indisponível.

\section{CONCLUSÃo}

Este trabalho procurou levantar evidências que pudessem respaldar o objetivo deste artigo que foi o de identificar se a aplicação da sistemática da "Árvore de Perdas" do TPM serviu como forma de identificação de perdas e oportunidades para trazer retorno a uma empresa do setor petroquímico - estudada.

Em geral, para um negócio como o petroquímico, onde a produção em altos volumes é um fator de competitividade, a análise das perdas de produção por indisponibilidade ou por capacidade - por não produzir na capacidade máxima - é fundamental para que se possa atuar preventivamente na confiabilidade de equipamentos e processos. Além disso, perdas por qualidade, que na maioria das vezes recaem em re-processo ou degradação de preços, afetam diretamente os custos e, na maioria das vezes, em perda de capacidade. O modelo proposto por Suzuki (1994) e por Takahashi e Osada (1993) para o cálculo do Índice de Eficiência Global (IEG) mostrou-se aplicável na empresa estudada por ser capaz de mostrar onde estariam os principais pontos de perda no IEG. Um outro ponto do modelo da árvore de perdas aplicado à empresa em estudo foi o da identificação dos pontos de ineficiência no consumo de matérias-primas, utilidades e materiais auxiliares. Para a indústria petroquímica, principalmente a primeira geração, onde os produtos se assemelham a commodities, a estratégia competitiva mais utilizada é a liderança em custos. Sendo assim, torna-se fundamental para uma empresa desta indústria saber identificar onde seu processo produtivo pode ser otimizado de forma a, sistematicamente, reduzir as perdas relativas a consumos de materiais e energia que impactam os custos. Pequenas adaptações tiveram que ser feitas no modelo implantado na empresa, com o objetivo de adequar a realidade das perdas da UN3 ao modelo teórico e, com isso, obter benefícios para o negócio. 
A árvore de perdas desenvolvida pela empresa mostrou-se uma sistemática eficiente de identificação e priorização dos pontos de perda a serem atacados.

\section{REFERÊNCIAS}

ABIQUIM. Sobre projetos de investimento (2001-2006) no seguimento de produtos químicos de uso industrial, da edição de out.2001 do departamento de Economia.

ARAGÃO, Irlam. Conceitos, premissas, características e treinamento em sistemáticas de melhoria. Documento produzido em Camaçari 2003 na empresa "Petroq1" (Desenvolvimento_Sistemáticas.ppt)

ARAGÃO, Irlam e EDE, Rubem. Definição de capacidade, índice de eficiência global e perdas de capacidade. Documento produzido em Camaçari 2003 na empresa "Petroq1"

(GAP_conceitos_iniciais.ppt)

Qualidade no sistema de produção. Apresentação eletrônica feita

. Projeto Petroq1.xls. Planilha eletrônica contendo o modelo matemático da árvore de perdas da empresa

Arvore de Perdas Atualização 2002. Apresentação eletrônica feita (Arvore_Petroq1_2002.ppt)

ASSAF NETO, Alexandre. Finanças corporativas e valor. São Paulo: Atlas 2003

BORNIA, Antonio Cezar. Análise gerencial de custos em empresas modernas. Porto Alegre: Bookman, 2002

CASTRO, Antonio Barros de...[et al.]. O futuro da indústria no Brasil e no mundo: os desafios do século XXI . Rio de Janeiro: Campus, 1999. 334 p.

CARRIJO, J. R. S. Administração Avançada. Apostilha ITE, 2001.

D’ÁVILA, Saul Gonçalves - A indústria Petroquímica brasileira, Faculdade de Engenharia Química da Unicamp, Campinas 2002 Disponível em: <http://www.comciencia.br/reportagens/petroleo/pet21.shtml> último acesso em: 14/01/04 às $9: 17$.

EASTERBY-SMITH, M. et al.. Management research: a introduction. London: Sage, 1991

ENSSLIN, L.; MONTIBELLER NETO, G.; NORONHA, S.M. Apoio a decisão: sistemáticas para estruturação de problemas e avaliação multicritério de alternativas. Florianópolis: Insular, 2001

FURTADO, João. Estudo da competitividade de cadeias integradas no Brasil: impactos das zonas de livre comércio. Campinas: Universidade Estadual de Campinas, Fevereiro 2003 
GUERRA, Oswaldo Ferreira. Estudo de competitividade da Indústria Brasileira: competitividade da indústria petroquímica. Fundação Economia de Campinas - FECAMP: Campinas, 1993

IEDI. A política de desenvolvimento industrial. 2002

IMAI, Yassuo - TPM como estratégia empresarial. São Paulo: IMC Internacional, 2000.

IMAI, Masaaki - Gemba Kaizen: Estratégias e técnicas do Kaizen no piso de fábrica. São Paulo: IMAM, 1996.

KÖCHE, J.C.. Fundamentos de metodologia científica: teoria da ciência e prática da pesquisa. Petrópolis, RJ: Vozes, 2001.

LANDRY, M. A note of the concept of 'problem'. Organization studies, v.16, n.2, p.315343

LIKER, Jeffrey K. O modelo Toyota: 14 princípios de gestão do maior fabricante do mundo. Trad. Lene Belon Ribeiro. Porto Alegre: Bookman, 2005.

MGMC - Manual de Gerenciamento da Manutenção e Confiabilidade, Empresa Petroq1: Salvador, 2004

MONTEIRO FILHA, Dulce Corrêa. A contribuição do BNDES na formação da estrutura setorial da indústria brasileira (1952-1989). Tese de doutorado. Rio de Janeiro: IEI/UFRJ, 1994.

MONTENEGRO, Ricardo Sá Peixoto; MONTEIRO FILHA, Dulce Corrêa; GOMES, Gabriel Lourenço. Indústria Petroquímica Brasileira: em busca de novas estratégias empresariais. Estudo realizado pelo Departamento de Análise do Complexo Químico do BNDES, 2002.

O setor petroquímico. parte do Clipping: Panorama geral da indústria petroquímica, FTE. Salvador, 2003

MONTIBELLER NETO, Gilberto. Mapas cognitivos difusos para o apoio a decisão: uma metodologia integrada para a construção de problemas e exploração do impacto de alternativas nos valores do tomador de decisão. Tese de doutorado em Engenharia de Produção da Universidade Federal de Santa Catarina, 2000.

NAKASATO, K. $\mathbf{1 5}^{\circ}$ Curso de Formação de Facilitadores em TPM. IM\&C Internacional. São Paulo, 2001.

OHNO, Taiichi. O sistema Toyota de produção: além da produção em larga escala. Trad. Cristina Schumacher. Porto Alegre: Artes Médicas, 1997.

PALMEIRA, Jorge Nassar. A manutenção produtiva total: o caso da Eletronorte. 2001. Dissertação (Mestrado em Administração) - Programa de Mestrado Executivo em Administração, FVG, Brasília.

PERRONE, Otto Vicente. A petroquímica brasileira e alguns dos seus mitos. Revista Petro\&química, no 234. 
PESTANA DA COSTA, Aluízio. Petroquímica brasileira: a história do seu desenvolvimento. Revista brasileira de engenharia química, nov. 1995.

PETRI, Sérgio M.. Modelo para apoiar a avaliação das abordagens de gestão de desempenho e sugerir aperfeiçoamentos: sob a ótica construtivista. TESE (Doutorado em Engenharia de Produção). Universidade Federal de Santa Catarina, 2005.

ROBINSON, Charles J.; GINDER, Andrew P. Implementing TPM: The North American Experience, New York: Productivity Press, 1995

RODRIGUES, Carlos Alberto. Perspectivas de reestruturação da petroquímica brasileira. parte do Clipping: Panorama geral da indústria petroquímica, FTE. Salvador, 2003

ROY, B. Decision science or decision-aid science? European Journal of Operational Research. V66 p184-203, 1993.

1996. Multicriteria methodology for decision aiding. Kluwer Academic Publisher,

On operational research and decision aid. European Journal of Operational Research. V73 p.23-26, 1994.

SABBATINI, Rodrigo et al. A internacionalização de empresas no capitalismo contemporâneo: breves notas sobre a inserção competitiva da indústria petroquímica brasileira. Campinas : Faculdade de Campinas, 2003

SAKAGUCHI, Mitsuo. Concepts of TPM parts I, II and III and Challenge requirements. Revista JIPM, Tokyo, v.25, p. 9-12, out.2001.

SHINGO, Shingeo. O sistema Toyota de Produção: sob o ponto de vista da engenharia de produção. Trad. Eduardo Schaan. Porto Alegre: Artes Médicas, 1996.

SPIEGEL, Murray R. Estatística. Rio de Janeiro. Ao livro Técnico, 1969.

SUZUKI, Tokutaro - TPM in Process industries. Portland, USA: Produtivity Press, 1994.

TAKAHASHI, Yosikazu; OSADA, Takashi. MPT - Manutenção Produtiva Total. São Paulo: IMAM, 1993.

TAVARES, Maria da Conceição. Ciclo e crise: o movimento da recente industrialização brasileira. Campinas, SP: Unicamp, 1998.

TRIVINOS, A. N. S. Introdução à pesquisa em ciências sociais: a pesquisa qualitativa em educação. São Paulo: Atlas, 1987. Introdução à pesquisa em ciências sociais. São Paulo: Atlas, 1992

YIN, R.K. Estudo de caso: planejamento e métodos. Tradução Daniel Grassi. 2. ed. Porto Alegre: Bookman, 2001.

Artigo recebido em 30/06/2005 e aceito para publicação em 21/08/2007 